\title{
DIVERSIDADE E DENSIDADE DE ESPÉCIES VEGETAIS DA CAATINGA COM DIFERENTES GRAUS DE DEGRADAÇÃo NO MUNICÍPIO de FLORESTA, Pernambuco, Brasil
}

\author{
Maria de Fátima de Araújo Vieira Santos ${ }^{1,4}$, Tassiane Novacosque Feitosa Guerra ${ }^{2}$, \\ Maria Carolina Sotero ${ }^{3} \&$ Jamile Inácio Noronha dos Santos ${ }^{3}$
}

\begin{abstract}
RESUMO
(Diversidade e densidade de espécies vegetais da caatinga com diferentes graus de degradação no município de Floresta, Pernambuco, Brasil) Foram identificados padrões florísticos e estruturais relacionados à degradação pelo uso antrópico da caatinga a partir da seleção de comunidades vegetais em três ambientes: degradado, medianamente degradado e conservado. As plantas foram amostradas em três estratos verticais: lenhosas altas (altura $\geq 3 \mathrm{~m}$ ), lenhosas baixas $(50 \mathrm{~cm} \leq$ alt. $<3 \mathrm{~m}$ ) e regeneração (alt. $<50 \mathrm{~cm}$ ). Foram estimadas riqueza, densidade e diversidade, e analisadas as curvas densidade-espécie e espécies-área. Como efeito da degradação, a vegetação apresentou menor número de espécies no estrato das lenhosas baixas: foram três espécies no ambiente degradado e 10 no conservado. Diversidade e densidade também foram menores no ambiente degradado ( 0,56 e $2.328 \mathrm{ind} /$ ha), do que no conservado (1,32 e 26.557 ind/ha). Dominaram o estrato das lenhosas baixas Malvastrum coromandellianum no ambiente degradado, e Cordia leucocephala e Croton mucronifolius no conservado. Não se detectou influência da degradação no estrato da regeneração, exceto pelo menor número de espécies no ambiente degradado, estimado pelo modelo espécie-área. São condições favoráveis ao desenvolvimento desse estrato: maior densidade dos estratos superiores e maior espessura do horizonte A do solo.
\end{abstract}

Palavras-chave: desertificação, diversidade de espécies, curva espécies-área, estratos verticais, Nordeste.

\section{Abstract}

(Diversity and density of plant species from differently degraded areas of caatinga at the Floresta municipality, Pernambuco, Brazil) Floristic and structural patterns related to anthropic degradation of the caatinga were identified based on the selection of plant communities in three situations: degraded, moderately degraded, and non-degraded. Plants were sampled from three vertical strata: upper woody (height $\geq 3 \mathrm{~m})$, lower woody $(50 \mathrm{~cm}$ $\leq$ height $<3 \mathrm{~m}$ ), and regeneration (height $<50 \mathrm{~cm}$ ). Richness, density, and diversity were estimated, and speciesdensity and species-area curves were analyzed. A decrease in the number of species was one of the effects of degradation: among the stratum of the lower woody plants, the number was three in the degraded area and $10 \mathrm{in}$ the non-degraded area. Diversity and density were also lower in the degraded area (0.56 and 2,328 ind/ha) compared to the non-degraded area (1.32 and 26,557 ind/ha). Malvastrum coromandellianum dominated the lower woody stratum in the degraded area, while Cordia leucocephala and Croton mucronifolius were dominant in non-degraded area. Influence from degradation was not detected in the regeneration stratum, except for the smaller number of species in the degraded environment that was estimated by the species-area model.

Key words: desertification, species diversity, species-area curve, vertical strata, Northeast.

\section{INTRODUÇÃO}

A capacidade da população humana de explorar sistemas naturais tem alcançado níveis alarmantes, causando grandes perturbações, muitas vezes suficientes para superar a capacidade homeostática do ecossistema explorado, chegando a comprometer o processo natural de sucessão ecológica e desencadear a degradação.
A região brasileira que apresenta clima semi-árido tem como vegetação predominante a caatinga. Nela, a economia está fortemente sustentada pela exploração dos recursos naturais, que, em geral, vem sendo desenvolvida sem qualquer tipo de preocupação conservacionista (Sampaio 2002). Para essa região não há estudos que mostrem até onde os processos de uso

Artigo recebido em 07/2008. Aceito para publicação em 02/2009.

${ }^{1}$ Universidade Federal Rural de Pernambuco, Departamento de Biologia, Área de Ecologia, R. Dom Manoel de Medeiros s/n, Dois Irmãos, Recife, 52050-310, PE, Brasil. fatimavs@ hotlink.com.br

${ }^{2}$ Mestranda em Ciências Florestais, Universidade Federal Rural de Pernambuco, Departamento de Ciência Florestal. ${ }^{3}$ Graduanda em Licenciatura em Ciências Biológicas, Universidade Federal Rural de Pernambuco.

${ }^{4}$ Endereço para correspondência: Rua Manuel de Carvalho 341/201, Aflitos, 52050-370, Recife, PE, Brasil. 
dos recursos naturais podem sustentar-se sem promover a degradação (Araújo et al. 2002).

As áreas susceptíveis à desertificação na Região Nordeste do Brasil se estendem pelas terras de clima semi-árido e sub-úmido seco, abrangendo cerca de $70 \%$ da região (Vasconcelos 2002). Um dos principais efeitos da desertificação é a diminuição da biodiversidade. A perda de espécies pode influenciar nas seqüências de comunidades necessárias ao desenvolvimento sucessional e, além disso, afetar a capacidade do ecossistema em se adaptar frente a futuras mudanças ambientais (Santos et al. 2003).

Os processos que levam o ecossistema em direção à maturidade proporcionam solos em equilíbrio com as condições ambientais, com maior estabilidade frente aos agentes da erosão. A degradação do ecossistema em zonas semi-áridas, em geral, causa a diminuição da qualidade do solo, juntamente com a regressão da sucessão ecológica, onde o estádio maduro retrocede para o início da sere. A comunidade torna-se menos densa, mais rica em plantas anuais com um sistema radicular menos desenvolvido, e oferece ao solo pequena proteção e escassa contribuição de matéria orgânica. Como resultado, a sucessão regressiva produz aumento da severidade dos processos de degradação do solo (Rodríguez et al. 2005).

A sucessão secundária está influenciada por eventos que afetam o recrutamento e a morte dos indivíduos. Nos ecossistemas semiáridos ela é lenta, porque o recrutamento depende principalmente de eventos chuvosos erráticos, e a escassez de água afeta de maneira mais severa as plântulas do que outros estágios vitais. O recrutamento depende da dispersão das sementes e da existência de um banco de sementes viáveis no solo. O estabelecimento pode ser facilitado por indivíduos adultos que rodeiam as plântulas, ou dificultado pela competição com as plantas vizinhas (Miranda et al. 2004).

O efeito da degradação ambiental na vegetação de caatinga tem sido pouco investigado. Estudos em áreas de caatinga da Paraíba (Pereira et al. 2001, 2003; Andrade et al. 2005) e do
Rio Grande do Norte (Maracajá et al. 2003) mostraram empobrecimento na composição florística, dominância de diferentes espécies entre os níveis de degradação, redução na densidade e no número de plantas nos estratos superiores a $3 \mathrm{~m}$ de altura.

Este estudo pretende caracterizar a vegetação de caatinga sobre Luvissolo em processo de desertificação, cuja história de uso está ligada ao sobrepastoreio e extração de lenha. Para isso propõe-se investigar o número de espécies, a densidade das populações, a diversidade de espécies e a dominância das comunidades, em três áreas com diferentes graus de antropização.

\section{Material e Métodos Área de estudo}

A zona de estudo abrangeu gradientes de degradação ambiental ligados ao sobre pastoreio e extração de lenha no município de Floresta, estado de Pernambuco, e foi selecionada pela interpretação de imagens de satélite geradas pela RRS (Recife Receiving Station - Departamento de Tecnologia Rural, Universidade Federal Rural de Pernambuco/ UFRPE) e durante expedições de campo. O município de Floresta localiza-se na mesorregião do São Francisco, apresenta extensas áreas degradadas e compõe um dos quatro núcleos de desertificação do Brasil, o núcleo de Cabrobó (Sampaio et al. 2003).

O clima predominante na zona de estudo é quente e semi-árido, BShw' segundo a classificação de Köppen, precipitação média anual de $500 \mathrm{~mm}$, chuvas de verão retardadas para o outono e temperatura média anual de $27^{\circ} \mathrm{C}$ (Andrade 1999).

De acordo com critérios de zonas homogêneas, as parcelas de amostragem foram alocadas em diferentes áreas, dentro de uma área maior de aproximadamente $420 \mathrm{~km}^{2}$, que apresentaram situações semelhantes com relação às condições climáticas, solo Luvissolo, altitude entre $334 \mathrm{~m}$ e $391 \mathrm{~m}$, declividade entre de $0 \%$ a $5 \%$, relevo suave ondulado, uso do solo pelo pastoreio extensivo e extração de lenha. 
O Luvissolo foi escolhido por ocupar grandes extensões de áreas cristalinas e relevo suave ondulado na região semi-árida $(13,3 \%)$ e porque é considerado altamente susceptível à erosão, em virtude da grande diferença textural entre os horizontes A e Bt (Jacomine 1996). Os Luvissolos são, em geral, rasos a pouco profundos, apresentam frequentemente revestimento pedregoso na superfície (pavimento desértico) ou na massa do solo e crosta superficial de 5 a $10 \mathrm{~mm}$ de espessura.

Para o estudo foram escolhidos três tipos de ambiente, com intensidade decrescente dos processos erosivos do solo: degradado, medianamente degradado e conservado. $\mathrm{O}$ ambiente degradado apresentou erosão laminar severa, sulcos frequentes e voçorocas; o medianamente degradado, erosão laminar ligeira a moderada, e o conservado, erosão laminar ligeira. Segundo Galindo (2007), que investigou os solos das áreas aqui estudadas, as características dos Luvissolos melhor relacionadas com as áreas degradadas foram a diminuição da profundidade do perfil, a redução da espessura do horizonte superficial ou sua eliminação total e a redução dos teores de carbono orgânico e nitrogênio total, resultantes da intensificação dos processos erosivos.

No ambiente degradado, a vegetação foi classificada como caatinga arbustiva aberta, esparsa, com alta intensidade de pastejo. No conservado, a vegetação foi descrita como caatinga arbóreo-arbustiva, muito densa e baixa ou pouco densa e mais alta, sendo que das três áreas amostradas duas eram cercadas e raramente pastejadas. O ambiente moderadamente degradado apresentou vegetação intermediária em relação aos demais ambientes.

O ambiente conservado foi escolhido pela presença da comunidade vegetal em estádio avançado da sucessão, considerado como representativo da vegetação testemunha em relação à atuação dos agentes da degradação e, por isso, serviu para as comparações com a vegetação degradada a fim de se obterem os padrões da vegetação em processo de desertificação (Santos et al. 2003).
Dentro do município de Floresta, os ambientes degradado e medianamente degradado foram amostrados em quatro locais, somando sete parcelas representativas de cada, separadas por distância variável, de no mínimo $50 \mathrm{~m}$ e no máximo $21 \mathrm{~km}$. As sete parcelas representativas do ambiente conservado foram distribuídas em três locais, separadas de no mínimo 50 m e no máximo 15 km (Fig. 1).

\section{Amostragem}

Em cada ambiente de estudo foram estabelecidas sete parcelas de $10 \mathrm{~m}$ x $20 \mathrm{~m}$. A vegetação foi amostrada em três estratos verticais distintos, com tamanhos de parcelas diferentes: lenhosas altas (altura $\geq 3 \mathrm{~m}$ ) em todos os $200 \mathrm{~m}^{2}$ de cada parcela; lenhosas baixas $(50 \mathrm{~cm} \leq$ alt. $<3 \mathrm{~m})$ em metade da área de cada parcela; e regeneração (alt. $<50$ $\mathrm{cm}$, incluiu as plântulas) em um conjunto de 18 subparcelas de $50 \mathrm{~cm}$ x $25 \mathrm{~cm}$, demarcadas no interior das quatro primeiras parcelas representativas de cada ambiente.

Em estudos de flora, em geral, são amostradas as plantas que apresentam possibilidade de serem identificadas, por isso as plântulas raramente são computadas. A plântula é o resultado da germinação da semente e constitui a fase juvenil do ciclo vital das plantas (Raven et al. 1978). Não podem ser identificadas botanicamente porque não existe referência nas exsicatas dos herbários. Neste estudo, optou-se por contabilizá-las nas subparcelas, como indicador das condições para o recrutamento nos ambientes de estudo.

As expedições de campo foram realizadas em duas campanhas, nos anos de 2005 e de 2006, no período correspondente à estação das chuvas na região, de março a junho, quando coletou-se material botânico para identificação.

\section{Tratamento dos dados}

A identificação botânica seguiu o sistema de classificação de Cronquist (1981). Foram montadas exsicatas e incorporadas ao herbário Professor Vasconcelos Sobrinho/UFRPE, numeradas de 48603 a 48650. 
Os dados foram tomados por estrato vertical. No item densidade e diversidade de espécies, os parâmetros foram estimados através das suas médias. Para as lenhosas altas e baixas calcularam-se as médias de sete parcelas $(n=7)$ e, para o estrato da regeneração, quatro réplicas $(n=4)$, cada uma representada pelo conjunto das 18 subparcelas. Desta forma, estimaram-se o número de espécies (S), a densidade (D), a diversidade de Shannon \& Wiener $\left(\mathrm{H}^{\prime}=-\Sigma\right.$ pi. ln pi) e a equabilidade de Pielou $\left(E=H^{\prime} / \mathrm{lnS}\right)$, seguindo as recomendações de Martins \& Santos (2000).

Do ponto de vista florístico, foram comparadas as espécies presentes nos três tipos de ambiente mediante o índice de similaridade de Sørensen. A distribuição dos indivíduos entre as espécies foi representada pelas curvas densidade-espécie, tendo na abscissa as espécies amostradas em ordem decrescente de abundância, e na ordenada a abundância de cada uma (Margalef 1994).

Nas curvas espécies-área, cada ponto relacionou o número acumulado de novas espécies ao incremento da área correspondente a uma nova parcela. Essa relação foi analisada segundo a função: $S=c \mathrm{~A}^{z}$, em que $\mathrm{S}$ é o número de espécies; A é a área; $c$ é a ordenada na origem e $z$ relaciona o aumento do número de espécies ao incremento da área amostrada. Os valores de $\mathrm{S}$ e A foram transformados em logaritmo neperiano e submetidos à análise de regressão para a determinação do ajuste da função $\left(\mathrm{R}^{2}\right)$ e dos coeficientes ( $c$ e $z$ ) (Williamson 1988). Com a obtenção das equações foram estimados números de espécies por área amostrada com a finalidade de comparar os três ambientes.

As comparações entre os ambientes foram realizadas mediante Anova (Análise da Variância) de um fator e aplicou-se o teste de Tukey para

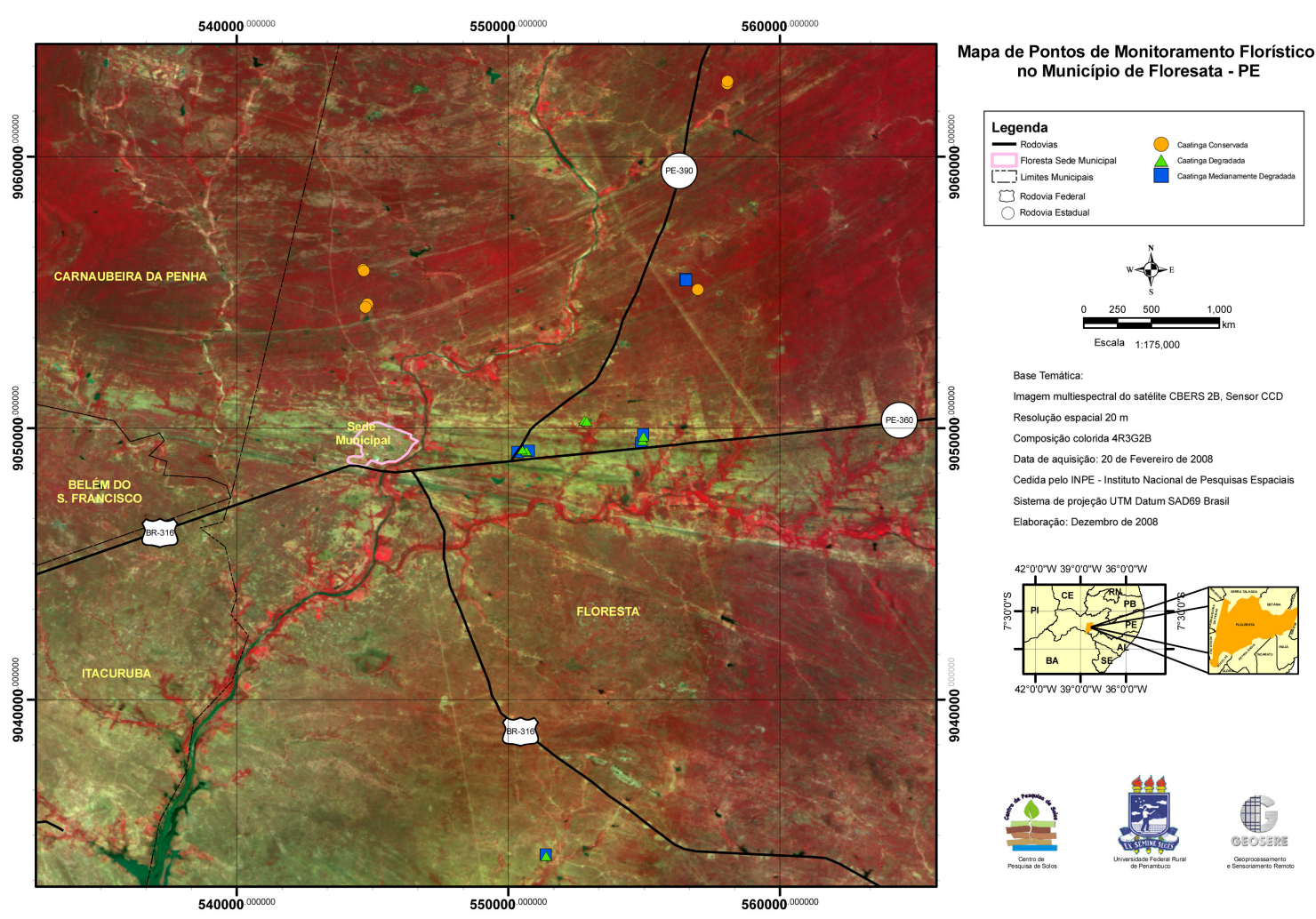

Figura 1 - Área de estudo com localização das 21 parcelas de amostragem nos ambientes degradado, medianamente degradado e conservado, no município de Floresta, Pernambuco, Brasil.

Figure 1 - Study site. Localization of the 21 analyzed plots at the degraded, moderately degraded and non-degraded areas at Floresta Municipality, Pernambuco, Brasil. 
detectar as diferenças entre eles. Previamente à aplicação da Anova, procedeu-se à verificação da normalidade dos dados. A análise de regressão, o estudo da normalidade e aplicação da Anova foram realizados com o uso do pacote estatístico SPSS para Windows versão 8.0.

\section{Resultados e Discussão Florística}

No total foram amostradas 67 espécies, pertencentes a 28 famílias. Entre elas, 16 espécies foram descritas como endêmicas da caatinga por Giulietti et al. (2002). O ambiente degradado apresentou o menor número de espécies, 28, o medianamente degradado 44 espécies e o conservado, o mais rico, com 50 espécies (Tab. 1). Esses resultados apontam que o processo de degradação vai sendo acompanhado pelo empobrecimento da flora, o que também foi observado em outros estudos (Pereira et al. 2001; Maracajá et al. 2003; Pereira et al. 2003).

Os três ambientes apresentaram em comum 15 espécies. O número de espécies exclusivas foi menor no ambiente degradado (três) do que no medianamente degradado (cinco), ou no conservado (19 espécies) (Tab. 1). A semelhança florística entre a vegetação dos ambientes degradado e conservado foi de $38,5 \%$, segundo o índice de Sørensen, indicando floras distintas.

No município de São João do Cariri na Paraíba, Andrade et al. (2005) estudaram duas fitofisionomias de caatinga com diferentes histórias de uso, incluindo indivíduos com circunferência à altura da base $\geq 10 \mathrm{~cm}$. Na área em bom estado de conservação, os autores amostraram mais que o dobro do número de espécies (15) encontradas na área em avançado estado de degradação (seis).

No presente estudo, as famílias mais representativas foram Euphorbiaceae, com 10 espécies; Poaceae, com sete; Cactaceae, Rubiaceae e Malvaceae com cinco; e Sterculiaceae, com três. Outras sete famílias apresentaram duas espécies e as 15 famílias restantes apresentaram uma única espécie
(Tab. 1). A família Euphorbiaceae tem sido encontrada em outras comunidades de caatinga com número elevado de espécies (Santos et al. 1992; Araújo et al. 1995; Rodal et al. 2005).

\section{Curvas Densidade-Espécie}

$\mathrm{Na}$ fase inicial da regeneração secundária da vegetação, um número relativamente reduzido de espécies ocupa nichos muito extensos no ecossistema. Em contraste, nos estádios mais avançados, em muitos casos, observa-se que um número relativamente grande de espécies reparte um grande número de nichos, que são mais reduzidos (Magurran 1989).

As curvas de densidade-espécie para os três estratos verticais (lenhosas altas, lenhosas baixas e da regeneração) caracterizaram-se por pendentes acentuadas na parte superior, indicando forte dominância de poucas espécies, e concentração de um número maior de espécies na parte inferior, exceto para as lenhosas altas no ambiente degradado (Fig. 2).

Ocorreu alta dominância de Caesalpinia pyramidalis no estrato das lenhosas altas dos três ambientes, correspondendo a 50, 80 e 75\% de densidade relativa nos ambientes degradado, medianamente degradado e conservado, respectivamente (Tab. 2, Fig. 2a). No estrato das lenhosas baixas, a maior dominância, no ambiente degradado, foi de Malvastrum coromandellianum, que alcançou a densidade relativa de 53\%. O grau de dominância desse estrato nos outros dois ambientes foi aproximado, porém as espécies mais abundantes foram diferentes. No medianamente degradado, $M$. coromandellianum (37\%) e C. pyramidalis (17\%), e no conservado, Cordia leucocephala (35\%) e Croton mucronifolius (19\%) (Tab. 2, Fig. 2b).

$\mathrm{O}$ estrato da regeneração do ambiente degradado apresentou a curva de pendente mais acentuada, refletindo a dominância de Aristida adscensionis, com $61 \%$ de densidade relativa. Esta espécie teve dominância também no ambiente medianamente degradado, com $47 \%$ da densidade, seguida por Bernardia sidoides, com $19 \%$. Esta última foi a espécie com maior 
Tabela 1 - Densidade absoluta das espécies por estrato vertical: lenhosas altas, lenhosas baixas e regeneração; e por ambiente: degradado (D), medianamente degradado (MD) e conservado (C), situados no município de Floresta, Pernambuco, Brasil. Indicação da presença (*).

Table 1 - Absolute densities per vertical strata (upper woody, lower woody and regeneration) on degraded (D), moderately degraded (MD) and non-degraded (C) areas at Floresta Municipality, Pernambuco, Brasil.

\begin{tabular}{|c|c|c|c|c|c|c|c|c|c|c|}
\hline \multirow[t]{2}{*}{ Espécie } & \multirow[t]{2}{*}{ Família } & \multicolumn{3}{|c|}{$\begin{array}{l}\text { Lenhosas } \\
\text { altas } \\
\text { (ind/ha) }\end{array}$} & \multicolumn{3}{|c|}{$\begin{array}{c}\text { Lenhosas } \\
\text { baixas } \\
\text { (ind/ha) }\end{array}$} & \multicolumn{3}{|c|}{$\begin{array}{l}\text { Estrato da } \\
\text { regeneração } \\
\left(\mathrm{ind} / \mathbf{m}^{2}\right)\end{array}$} \\
\hline & & D & MD & $\mathbf{C}$ & D & MD & $\mathbf{C}$ & D & MD & $\mathbf{C}$ \\
\hline Alternanthera tenella Colla & Amaranthaceae & - & - & - & - & - & - & 1 & 8 & - \\
\hline Aristida adscensionis L. & Poaceae & - & - & - & - & - & - & 79 & 104 & 0 \\
\hline Aristida elliptica (Nees) Kunth & Poaceae & - & - & - & - & - & - & 20 & 1 & - \\
\hline Aspidosperma pyrifolium Mart. & Apocynaceae & 14 & 43 & 7 & 271 & 1414 & 1229 & - & 0 & 0 \\
\hline Ayenia erecta Mart. ex K. Schum. & Sterculiaceae & - & - & - & - & - & - & 1 & - & - \\
\hline $\begin{array}{l}\text { Bernardia sidoides (Klotzsch) } \\
\text { Müll. Arg. }\end{array}$ & Euphorbiaceae & - & - & - & - & - & - & - & 42 & 48 \\
\hline $\begin{array}{l}\text { Commiphora leptophloeos (Mart.) } \\
\text { J. B. Gillett }\end{array}$ & Burseraceae & - & - & 43 & - & - & - & - & - & - \\
\hline $\begin{array}{l}\text { Caesalpinia microphylla Mart. } \\
\text { ex G. Don }\end{array}$ & Caesalpiniaceae & - & 14 & - & - & 43 & 14 & - & - & - \\
\hline Caesalpinia pyramidalis Tul. & Caesalpiniaceae & 21 & 443 & 757 & 600 & 2171 & 843 & 0 & 0 & - \\
\hline Chamaesyce hyssopifolia (L.) Small & Euphorbiaceae & - & - & - & - & - & - & - & - & 2 \\
\hline Chamaesyce thymifolia (L.) Millsp. & Euphorbiaceae & - & - & - & - & - & - & 1 & 5 & 1 \\
\hline Cleome guianensis Aubl. & Capparaceae & - & - & - & - & - & - & 0 & 1 & - \\
\hline $\begin{array}{l}\text { Cleome lanceolata (Mart. \& Zucc.) } \\
\text { H.H. Iltis }\end{array}$ & Capparaceae & - & - & - & - & - & - & 0 & - & - \\
\hline $\begin{array}{l}\text { Cnidoscolus bahianus (Ule) } \\
\text { Pax \& K. Hoffm. }\end{array}$ & Euphorbiaceae & 7 & 36 & 71 & - & 86 & 14 & - & - & - \\
\hline Commelina erecta $\mathrm{L}$. & Commelinaceae & - & - & - & - & - & - & - & 1 & 2 \\
\hline Cordia leucocephala Moric. & Boraginaceae & - & - & - & - & 300 & 9343 & - & - & 1 \\
\hline Croton heliotropiifolius Kunth & Euphorbiaceae & - & - & 57 & - & - & 671 & - & - & - \\
\hline Croton hirtus L' Hér. & Euphorbiaceae & - & - & - & - & - & - & - & - & 34 \\
\hline Croton mucronifolius Müll. Arg. & Euphorbiaceae & - & - & 14 & 14 & 329 & 5129 & - & 0 & 1 \\
\hline Croton rhamnifolius Willd & Euphorbiaceae & - & - & - & - & 314 & 371 & - & - & - \\
\hline Cyperus uncinulatus Schrad. ex Nees & Cyperaceae & - & - & - & - & - & - & - & 1 & 11 \\
\hline Diodia teres Walter & Rubiaceae & - & - & - & - & - & - & - & - & 12 \\
\hline Encholirium sp. & Bromeliaceae & - & - & - & 57 & 243 & - & - & - & - \\
\hline Enteropogon mollis (Nees) Clayton & Poaceae & - & - & - & - & - & - & - & 1 & 34 \\
\hline Evolvulus sp. & Convolvulaceae & - & - & - & - & - & - & - & 0 & - \\
\hline Heliotropium sp. & Boraginaceae & - & - & - & - & - & - & 1 & - & - \\
\hline Herissantia crispa (L.) Brizicki & Malvaceae & - & - & - & - & 414 & 643 & - & - & 1 \\
\hline Herissantia tiubae (K. Schum.) Brizicky & Malvaceae & - & - & - & - & 157 & 57 & - & 1 & 12 \\
\hline Hyptis atrorubens Poit. & Lamiaceae & - & - & - & - & - & - & - & - & 0 \\
\hline Indeterminada 1 & - & - & - & - & - & - & - & - & 0 & - \\
\hline Indeterminada 2 & - & - & - & - & - & - & 14 & - & - & - \\
\hline Jatropha pohliana Müll. Arg. & Euphorbiaceae & - & 14 & 7 & 114 & 700 & 57 & - & 0 & 0 \\
\hline Malvaceae 1 & Malvaceae & - & - & - & - & - & 29 & - & - & - \\
\hline $\begin{array}{l}\text { Malvastrum coromandelianum } \\
\text { (L.) Garcke }\end{array}$ & Malvaceae & - & - & - & 1229 & 4729 & 4214 & 2 & 5 & 2 \\
\hline $\begin{array}{l}\text { Melocactus bahiensis (Britton } \\
\text { \& Rose) Luetzelb. }\end{array}$ & Cactaceae & - & - & - & & - & 14 & 0 & - & - \\
\hline Melochia tomentosa $\mathrm{L}$. & Sterculiaceae & - & - & - & - & 1386 & 86 & 2 & 0 & 1 \\
\hline
\end{tabular}




\begin{tabular}{|c|c|c|c|c|c|c|c|c|c|c|}
\hline \multirow[t]{2}{*}{ Espécie } & \multirow[t]{2}{*}{ Família } & \multicolumn{3}{|c|}{$\begin{array}{c}\text { Lenhosas } \\
\text { altas } \\
\text { (ind/ha) }\end{array}$} & \multicolumn{3}{|c|}{$\begin{array}{l}\text { Lenhosas } \\
\text { baixas } \\
\text { (ind/ha) }\end{array}$} & \multicolumn{3}{|c|}{$\begin{array}{l}\text { Estrato da } \\
\text { regeneração } \\
\left(\text { ind } / \mathbf{m}^{2}\right)\end{array}$} \\
\hline & & D & MD & $\mathbf{C}$ & D & MD & $\mathbf{C}$ & D & MD & $\mathbf{C}$ \\
\hline Mimosa tenuiflora (Willd.) Poir. & Mimosaceae & - & - & 29 & - & 14 & 129 & - & 0 & - \\
\hline Myracrodruon urundeuva Allemão & Anacardiaceae & - & - & 14 & - & - & - & - & - & - \\
\hline Neoglaziovia variegata (Arruda) Mez & Bromeliaceae & - & - & - & - & - & 2657 & - & - & 0 \\
\hline Noisettia longifolia Kunth & Violaceae & - & - & - & - & - & - & - & 2 & - \\
\hline Oсітит sp. & Lamiaceae & - & - & - & - & - & 29 & - & - & - \\
\hline Opuntia inamoena K. Schum. & Cactaceae & - & - & - & - & - & - & 2 & 0 & 2 \\
\hline Opuntia palmadora Britton \& Rose & Cactaceae & - & - & - & 29 & 29 & 200 & - & 0 & 0 \\
\hline Oxalis sp. & Oxalidaceae & - & - & - & - & - & - & - & - & 0 \\
\hline Paspalum fimbriatum Kunth & Poaceae & - & - & - & - & - & - & 1 & 7 & 2 \\
\hline Pectis congesta Baker & Asteraceae & - & - & - & - & - & - & 7 & 17 & - \\
\hline $\begin{array}{l}\text { Pilosocereus gounellei (F.A.C. } \\
\text { Weber) Byles \& G.D. Rowley }\end{array}$ & Cactaceae & - & - & - & 14 & 57 & - & - & - & - \\
\hline Pilosocereus sp. & Cactaceae & - & - & 7 & - & - & - & - & - & - \\
\hline Piriqueta racemosa (Jacq.) Sweet & Turneraceae & - & - & - & - & - & - & - & - & 1 \\
\hline Poaceae 1 & Poaceae & - & - & - & - & - & - & - & 4 & 0 \\
\hline Poaceae 2 & Poaceae & - & - & - & - & - & - & - & - & 1 \\
\hline Portulaca elatior Mart. ex Rohrb. & Portulacaceae & - & - & - & - & - & - & 1 & 1 & 0 \\
\hline Portulaca sp. & Portulacaceae & - & - & - & - & - & - & - & 1 & 0 \\
\hline Rubiaceae 1 & Rubiaceae & - & - & - & - & - & - & - & 1 & 1 \\
\hline Rubiaceae 2 & Rubiaceae & - & - & - & - & - & - & - & 0 & - \\
\hline Rubiaceae 3 & Rubiaceae & - & - & - & - & - & - & 1 & 3 & - \\
\hline Sida cordifolia $\mathrm{L}$. & Malvaceae & - & - & - & - & - & 86 & - & - & - \\
\hline Spigelia sp. & Loganiaceae & - & - & - & - & - & - & 1 & 4 & 28 \\
\hline $\begin{array}{l}\text { Stachytarpheta cayennensis } \\
\text { (Rich) Vahl. }\end{array}$ & Verbenaceae & - & - & - & - & - & - & - & 0 & - \\
\hline Tragus berteronianus Schult. & Poaceae & - & - & - & - & - & - & 9 & 8 & 2 \\
\hline Turnera pumilea $\mathrm{L}$. & Turneraceae & - & - & - & - & - & - & 1 & 0 & - \\
\hline Waltheria rotundifolia Schrank & Sterculiaceae & - & - & - & - & 229 & 643 & - & - & 2 \\
\hline Riccia sp. & Ricciaceae & - & - & - & - & - & - & - & - & $*$ \\
\hline Selaginella convoluta (Arn.) Spring & Selaginellaceae & - & - & - & - & - & - & $*$ & $*$ & - \\
\hline \multirow[t]{2}{*}{ Selaginella sellowii Hieron. } & Selaginellaceae & - & - & - & - & - & - & - & $*$ & $*$ \\
\hline & Plântulas & - & - & - & - & - & - & 1 & 5 & 13 \\
\hline
\end{tabular}

densidade relativa no ambiente conservado, $24 \%$, seguida por Enteropogon mollis e Croton hirtus, ambas com 16\% (Tab. 2, Fig. 2c).

Caesalpinia pyramidalis destaca-se pela alta densidade em diferentes locais de caatinga, como relataram Alcoforado-Filho et al. (2003), para Caruaru/PE; Andrade et al. (2005), para São João do Cariri/PB; e Santana \& Souto (2006), para Serra Negra do Norte/RN.

$\mathrm{Na}$ porção inferior das curvas (Fig. 2) estão representadas as espécies com as menores densidades relativas de cada ambiente. Populações de lenhosas baixas com densidade relativa inferior a $5 \%$ abrangeram
62,71 e $83 \%$ das espécies dos ambientes degradado, medianamente degradado e conservado, respectivamente. A porcentagem de espécies de lenhosas altas que apresentou densidade relativa inferior a $5 \%$ foi de $0,40 \mathrm{e}$ $70 \%$, nos ambientes degradado, medianamente degradado e conservado, respectivamente. Nos estudos realizados na caatinga com diferentes níveis de perturbação, por Andrade et al. (2005) e por Maracajá et al. (2003), áreas conservadas apresentaram maior porcentagem de espécies com densidade relativa inferior a $5 \%$ que áreas degradadas, situação semelhante a deste estudo. 

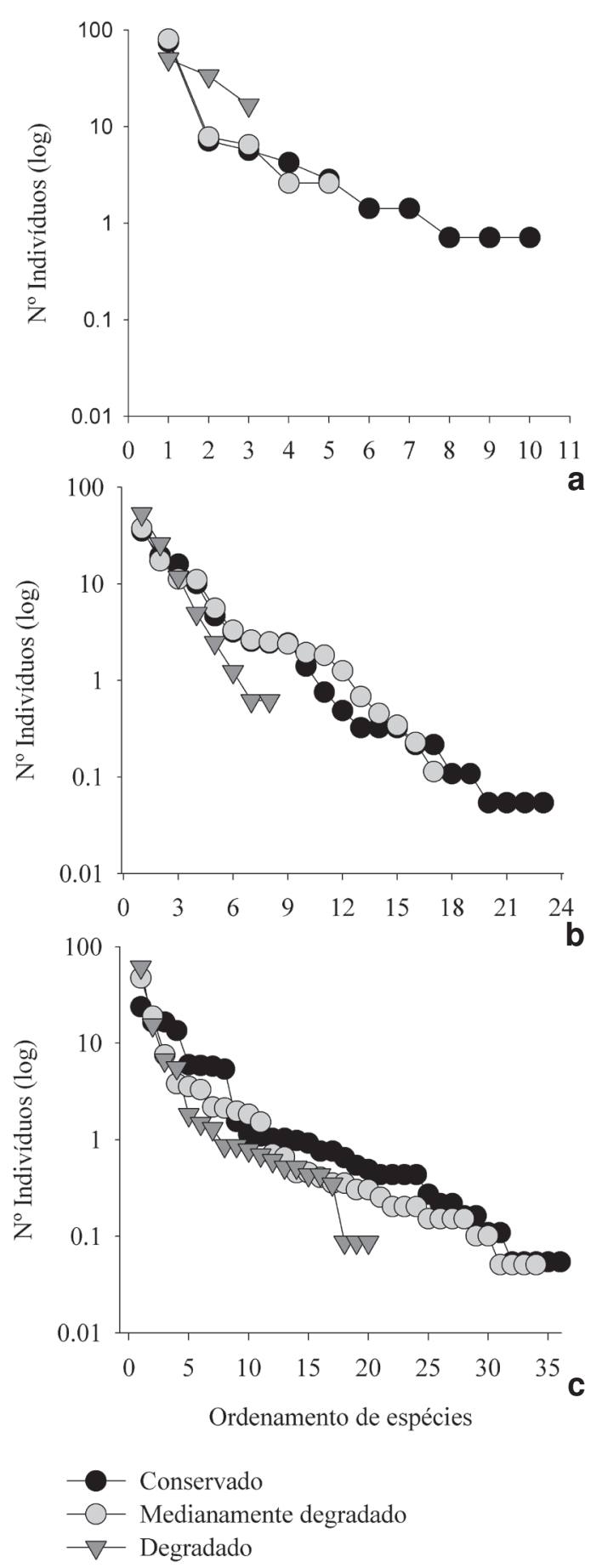

Figura 2 - Curvas densidade-espécie por estrato vertical, lenhosas altas (A), lenhosas baixas (B) e regeneração (C), nos ambientes conservado, medianamente degradado e degradado, situados no município de Floresta, Pernambuco, Brasil.

Figure 2 - Specie-density curves per vertical strata, upper woody (a), lower woody (b) and regeneration (c) on the degraded, moderately degraded and non-degraded areas at Floresta Municipality, Pernambuco, Brasil.
No estrato da regeneração, de forma mais acentuada que nos outros estratos, a curva densidade-espécie apresentou grande concentração de espécies na parte inferior. A proporção de espécies com densidade relativa inferior a $1 \%$ foi de $65 \%$ no degradado, e de $67,6 \%$ no medianamente degradado e no conservado (Fig. 2c).

O grande número de espécies raras é uma condição comum para a maioria dos ambientes analisados. O significado dessas espécies para o desenvolvimento da vegetação não é facilmente avaliado e deve haver diferentes explicações. Tais espécies podem se tornar mais abundantes como resposta a uma condição ambiental mais favorável, conferindo certa "habilidade" para o ecossistema se adaptar a mudanças das condições (Lovejoy 1988).

\section{Densidade e Diversidade de Espécies}

O baixo número de plantas lenhosas altas amostradas no ambiente degradado impossibilitou que entrassem na análise apresentada na Tabela 3. Neste estrato, o número médio de espécies por parcela foi maior no ambiente conservado (quatro espécies) do que no medianamente degradado (três espécies) $(\mathrm{F}=20,619 ; \mathrm{p}=0,000)($ Tab. 3).

No estrato das lenhosas baixas, o número médio de espécies por parcela foi maior no ambiente conservado (10) que no medianamente degradado (sete), e este apresentou maior número que o degradado (três espécies) $(\mathrm{F}=20,956 ; \mathrm{p}=0,000) . \mathrm{A}$ densidade média foi maior no ambiente conservado, (26.557 ind/ha) do que no degradado (2.329 ind/ha) e no medianamente degradado (8.357 ind/ha) $(\mathrm{F}=34,203 ; \mathrm{p}=$ $0,000)$. A diversidade média foi maior no ambiente conservado $(1,32)$ e no medianamente degradado $(1,38)$ que no degradado $(0,56)(\mathrm{F}$ $=12,016 ; \mathrm{p}=0,000)$. As diferenças na diversidade foram principalmente atribuídas ao número de espécies, já que a eqüabilidade não foi significativamente diferente entre essas comunidades. 
Tabela 2 - Densidade relativa (\%) das espécies mais abundantes de cada estrato vertical (lenhosas altas, lenhosas baixas e regeneração) dos ambientes degradado (D), medianamente degradado (MD) e conservado (C), situados no município de Floresta, Pernambuco, Brasil.

Table 2 - Relative density (\%) of the most abundant species per vertical strata (upper woody, lower woody and regeneration) on degraded (D), moderately degraded (MD) and non-degraded (C) areas at Floresta Municipality, Pernambuco, Brasil.

\begin{tabular}{llllllllll}
\hline Espécies & \multicolumn{3}{c}{ Lenhosas altas } & \multicolumn{3}{c}{ Lenhosas baixas } & \multicolumn{3}{c}{ Regeneração } \\
\multicolumn{1}{c}{ Ambientes } & D & MD & C & D & MD & C & D & MD & C \\
\hline Caesalpinia pyramidalis & 50,0 & 80,5 & 75,2 & 25,8 & 17,2 & 3,2 & 0,1 & 0,2 & - \\
Cnidoscolus bahianus & 16,7 & 6,5 & 7,1 & - & 0,7 & 0,1 & - & - & - \\
Croton heliotropiifolius & - & - & 5,8 & - & - & 2,5 & - & - & - \\
Aspidosperma pyrifolium & 33,3 & 7,8 & 0,7 & 11,7 & 11,2 & 4,6 & - & 0,1 & 0,1 \\
Cordia leucocephala & - & - & - & - & 2,4 & 35,2 & - & - & 0,4 \\
Croton mucronifolius & - & - & 1,4 & 0,6 & 2,6 & 19,3 & - & 0,2 & 0,4 \\
Malvastrum coromandelianum & - & - & - & 52,8 & 37,5 & 15,9 & 1,8 & 2,2 & 1,0 \\
Bernardia sidoides & - & - & - & - & - & - & - & 19,0 & 22,2 \\
Croton hirtus & - & - & - & - & - & - & - & - & 15,5 \\
Enteropogon mollis & - & - & - & - & - & - & - & 0,3 & 15,5 \\
Aristida adscensionis & - & - & - & - & - & - & 61,5 & 47,3 & 0,2 \\
\hline
\end{tabular}

Exceto a equabilidade, que não apresentou os atributos necessários à aplicação da Anova, o estrato da regeneração não apresentou diferença significativa entre as comunidades analisadas. Este resultado pode indicar a manutenção do potencial de regeneração da comunidade nos ambientes degradados, mas há outros aspectos a serem analisados.

O número de plântulas é um indicador da possibilidade de recuperação da vegetação. A menor densidade de plântulas, com $1 \mathrm{ind} / \mathrm{m}^{2}$ foi encontrada no ambiente degradado, seguida por $5 \mathrm{ind} / \mathrm{m}^{2}$ no medianamente degradado e $13 \mathrm{ind} / \mathrm{m}^{2}$ no ambiente conservado, mostrando que a degradação influenciou negativamente no potencial de recrutamento de novos indivíduos.

Para uma melhor avaliação seria necessário saber em que proporção as espécies dos estádios iniciais e avançados da sucessão ecológica estavam presentes, para formar uma idéia da possibilidade da evolução do processo.

Para o estrato das lenhosas baixas, a vegetação do ambiente degradado apresentou os maiores coeficientes de variação e a comunidade vegetal do ambiente conservado teve os menores coeficientes de variação para os quatro parâmetros analisados. No local de estudo, essa variabilidade pode estar associada à alternância de áreas com e sem recobrimento vegetal do solo.

\section{Curvas Espécies-Área}

As curvas espécies-área (Fig. 3) indicam uma importante propriedade da comunidade, que é a riqueza de espécies em relação ao aumento do tamanho da área amostrada, e as comunidades podem ser comparadas com relação a esses dados (Muller-Dombois \& Ellenberg 1974).

A partir de $1000 \mathrm{~m}^{2}$ de área amostral, o estrato das lenhosas altas, no ambiente conservado, não mais adicionou espécies às 10 acumuladas. Nessa mesma área, a comunidade degradada apresentou três espécies (Fig. 3a).

Em $400 \mathrm{~m}^{2}$ de área amostral para as lenhosas baixas, o ambiente degradado acumulou sete espécies, o moderadamente degradado 14 espécies e o conservado 21 espécies (Fig. 3b). A partir de $1,25 \mathrm{~m}^{2}$ de amostragem do estrato da regeneração, o ambiente degradado apresentou 
Tabela 3 - Valores médios por parcela de densidade absoluta (DA), número de espécies (S), índice de diversidade (H'), equabilidade (E) e respectivos coeficientes de variação (CV\%) dos três estratos verticais (lenhosas altas, lenhosas baixas e regeneração), nos ambientes degradado (D), medianamente degradado (MD) e conservado (C), no município de Floresta, Pernambuco, Brasil. As letras minúsculas diferentes, posicionadas na mesma linha indicam diferenças significativas entre os ambientes (teste de Tukey, $\alpha<5 \%$ ).

Table 3 - Mean values per plot of absolute density (DA), number of species (S), diversity index (H'), equitability (E) and respective coefficients of variation (CV\%) from the three vertical strata (upper woody, lower woody and regeneration) on the degraded (D), moderately degraded (MD) and non-degraded (C) areas at Floresta Municipality, Pernambuco, Brasil. Lowercases positioned at same line indicate significant differences among the areas (Tukey test, $\alpha<5 \%$ ).

\begin{tabular}{|c|c|c|c|c|c|c|}
\hline \multirow{2}{*}{$\begin{array}{l}\text { Estratos verticais } \\
\text { Parâmetros }\end{array}$} & \multicolumn{6}{|c|}{ Ambientes } \\
\hline & \multicolumn{2}{|l|}{ D } & \multicolumn{2}{|c|}{ MD } & \multicolumn{2}{|l|}{ C } \\
\hline & & CV\% & & CV\% & & CV\% \\
\hline \multicolumn{7}{|l|}{ Lenhosas altas } \\
\hline DA (ind/ha) & - & - & $550 \mathbf{a}$ & 85,6 & $1007 \mathbf{a}$ & 67,2 \\
\hline S & - & - & $3 \mathbf{a}$ & 30,6 & $4 \mathbf{b}$ & 25,8 \\
\hline $\mathrm{H}^{\prime}$ & - & - & $0,67 \mathbf{a}$ & 41,6 & $0,93 \mathbf{a}$ & 41,9 \\
\hline $\mathrm{E}$ & - & - & $0,75 \mathbf{a}$ & 32,0 & $0,66 \mathbf{a}$ & 36,3 \\
\hline \multicolumn{7}{|l|}{ Lenhosas baixas } \\
\hline DA (ind/ha) & $2.329 \mathbf{a}$ & 165,5 & $8.357 \mathbf{b}$ & 62,6 & $26.557 \mathbf{c}$ & 28,0 \\
\hline $\mathrm{S}$ & $3 \mathbf{a}$ & 71,2 & $7 \mathbf{b}$ & 26,1 & $10 \mathbf{c}$ & 23,1 \\
\hline $\mathrm{H}^{\prime}$ & $0,56 \mathbf{a}$ & 78,2 & $1,38 \mathbf{b}$ & 23,6 & $1,32 \mathbf{b}$ & 19,2 \\
\hline $\mathrm{E}$ & $0,72 \mathbf{a}$ & 42,0 & $0,71 \mathbf{a}$ & 20,3 & $0,58 \mathbf{a}$ & 15,6 \\
\hline \multicolumn{7}{|l|}{ Regeneração } \\
\hline DA $\left(\right.$ ind $\left./ m^{2}\right)$ & $128 \mathbf{a}$ & 42,2 & $219 \mathbf{a}$ & 11,2 & $204 \mathbf{a}$ & 105,5 \\
\hline $\mathrm{S}$ & $8 \mathbf{a}$ & 40,0 & $14 \mathbf{a}$ & 36,3 & $15 \mathbf{a}$ & 14,4 \\
\hline $\mathrm{H}^{\prime}$ & $1,00 \mathbf{a}$ & 48,8 & $1,22 \mathbf{a}$ & 44,6 & $1,87 \mathbf{a}$ & 14,0 \\
\hline $\mathrm{E}$ & 0,47 & 33,3 & 0,46 & 37,6 & 0,69 & 9,7 \\
\hline
\end{tabular}

oito espécies, e os ambientes medianamente degradado e conservado 11 espécies (Fig. 3c).

A variação entre os resultados dos diferentes ambientes amostrados reflete a diferença dos habitats utilizados pelas espécies, assim como dos organismos estudados (Williamson 1988). No ambiente conservado, o único estrato que atingiu claramente um valor assintótico foi o estrato das lenhosas altas. O fato de não ocorrer uma estabilização nítida da curva de acumulação de espécies nos outros estratos pode ser uma consequência das condições mais favoráveis do ambiente conservado, que em comparação com os ambientes degradados apresentou maior capacidade de armazenar água, horizonte superficial mais espesso e maior teor de carbono orgânico e nitrogênio total (Galindo 2007).

A relação espécies-área foi ajustada ao modelo potencial $\mathrm{S}=c \mathrm{~A}^{z}$. A regressão linear foi realizada em espaço ln-ln e obteve-se ajuste para seis dos nove casos testados, que apresentaram valores de $\mathrm{R}^{2}$ iguais ou superiores a $90 \%$. Os parâmetros c (interseção) e z (inclinação da reta) foram altamente significativos $(\mathrm{p}<0,0000)$ (Tab. 4). 

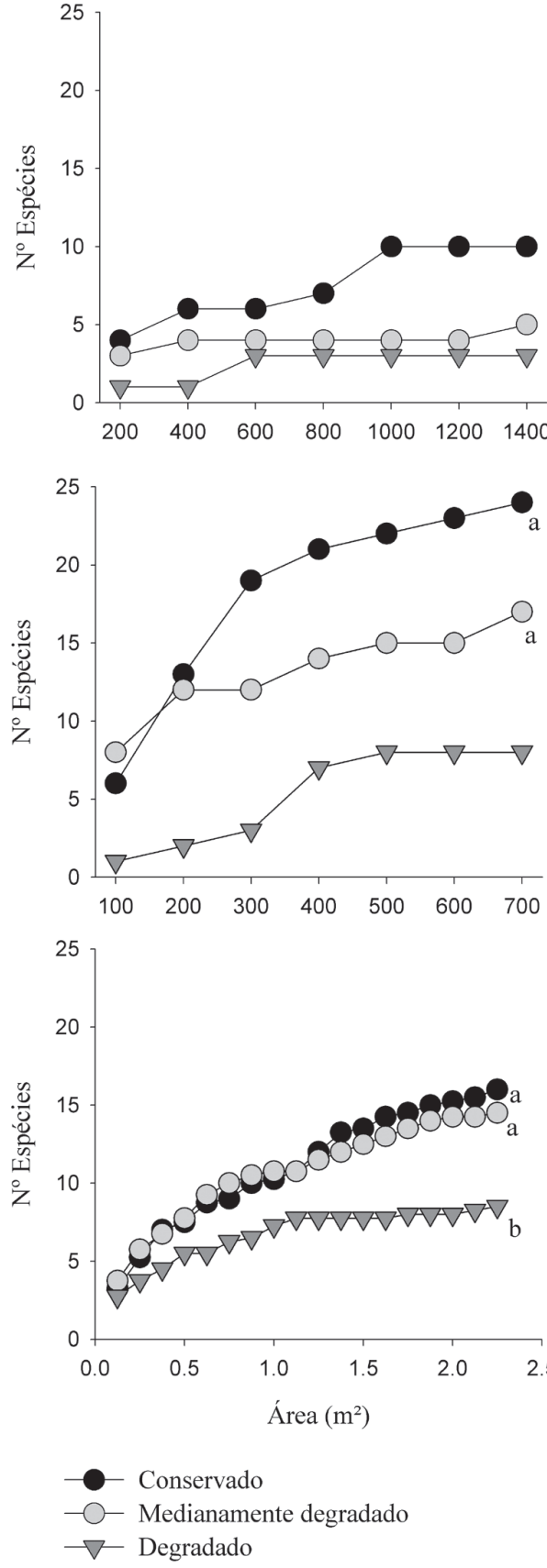

Figura 3 - Curvas espécies-área por estrato vertical, lenhosas altas (A), lenhosas baixas (B) e regeneração (C), nos ambientes conservado, medianamente degradado e degradado, situados no município de Floresta, Pernambuco, Brasil. As letras minúsculas diferentes indicam diferenças significativas entre os ambientes (teste de Tukey, $\alpha<5 \%$ ). Figure 3 - Species-area curves per vertical strata, upper woody (a), lower woody (b) and regeneration (c) on the degraded, moderately degraded and non-degraded areas at Floresta Municipality, Pernambuco, Brasil. Lowercases indicate significant differences among areas (Tukey test, $\alpha<5 \%$ ).
Tabela 4 - Ajuste da equação espécies-área, $\mathrm{R} 2$ e seus coeficientes $c$ e $z$, para três estratos verticais (lenhosas altas, lenhosas baixas e regeneração) da área estudada, nos ambientes degradado (D), medianamente degradado (MD) e conservado (C), situados no município de Floresta, Pernambuco, Brasil.

Table 4-Equation for the species-area relationship, $\mathrm{R}^{2}$ and its respective $c$ and $z$ coefficients, for the three vertical strata (upper woody, lower woody and regeneration) on the degraded (D), moderately degraded (MD) and non-degraded (C) areas at Floresta Municipality, Pernambuco, Brasil.

\begin{tabular}{llcl}
\hline $\begin{array}{l}\text { Estratos verticais } \\
\text { Parâmetros }\end{array}$ & $\mathrm{D}$ & MD & $\mathrm{C}$ \\
\hline Lenhosas altas & & & \\
$\quad c$ & - & - & 0,29 \\
$z$ & - & - & 0,49 \\
$\quad \mathrm{R}^{2}$ & - & - & 0,91 \\
Lenhosas baixas & & & \\
$\quad c$ & - & 1,67 & 0,28 \\
$z$ & - & 0,35 & 0,69 \\
$\mathrm{R}^{2}$ & - & 0,94 & 0,90 \\
Regeneração & & & \\
$\quad c$ & 6,63 & 10,53 & 10,70 \\
$z$ & 0,38 & 0,45 & 0,53 \\
$\mathrm{R}^{2}$ & 0,96 & 0,98 & 0,99 \\
\hline
\end{tabular}

Para uma mesma área inicial de $100 \mathrm{~m}^{2}$, o estrato das lenhosas baixas apresentou mais espécies no ambiente medianamente degradado do que no conservado, indicado pelo maior valor de $c$. Já o ambiente conservado apresentou maior valor de $z$, indicando que aumentando a área amostral acumulam-se mais espécies do que no medianamente degradado. No estrato da regeneração, os parâmetros $c$ e $z$ apresentaram valores decrescentes com a degradação (Tab. 4).

O número estimado de espécies pelo modelo espécies-área serviu para comparar, mediante Anova, o ambiente conservado e medianamente degradado, em relação às lenhosas baixas, e os três ambientes com relação ao estrato da regeneração. Neste estrato houve diferença entre o ambiente 
conservado e o degradado $(\mathrm{F}=11,299 ; \mathrm{p}=$ 0,000 ), indicando que o primeiro ambiente ganha espécies mais rapidamente com o aumento da área amostral que o segundo ambiente (Fig. 3c).

Embora não tenha havido diferenças no estrato da regeneração entre os três ambientes, com respeito a riqueza, densidade e diversidade, o ambiente conservado mostrou maior número estimado de espécies que o degradado, e essa diferença foi significativa.

\section{Conclusões}

O empobrecimento da flora com a degradação ambiental ocorre em todos os estratos da vegetação, mas é significativo apenas nos estratos superiores. A redução da flora é acompanhada da diminuição do índice de diversidade, que é significativa somente no estrato das lenhosas baixas.

As curvas densidade-espécie mostraram o fenômeno biológico da dominância em todos os ambientes, independentemente do estado de degradação. Porém, as espécies dominantes variam. O estrato das lenhosas baixas, no ambiente degradado, foi dominado por Malvastrum coromandelianum e, no ambiente conservado, por Cordia leucocephala e Croton mucronifolius. O estrato da regeneração, no ambiente degradado, foi dominado por Aristida adscensionis e, no conservado, por Bernardia sidoides, Croton hirtus e Enteropogon mollis.

Ainda que os valores de densidade da vegetação para os três estratos sejam superiores no ambiente conservado, os elevados coeficientes de variação fizeram com que esta diferença estrutural só fosse significativa para as plantas lenhosas baixas.

Não se detectou influência da degradação na riqueza, densidade, diversidade e equitatividade do estrato da regeneração, através da aplicação da Anova. Entretanto, usando o modelo espécie-área, encontra-se maior número estimado de espécies no ambiente conservado e no medianamente degradado do que no ambiente degradado. Significa dizer que as espécies do estrato da regeneração encontram condições mais favoráveis ao desenvolvimento na comunidade vegetal mais conservada, tais como, maior abundância de plantas nos estratos superiores, que podem servir de refúgio contra o pastoreio, e maior espessura do horizonte A do solo, o que propicia fornecimento de nutrientes e água.

\section{Agradecimentos}

Agradecemos à Universidade Federal Rural de Pernambuco pelas instalações e custeio das expedições de campo; aos especialistas do Instituto de Pesquisas Agropecuária de Pernambuco (IPA), da Universidade Federal Rural de Pernambuco, e da Universidade Federal de Pernambuco, pela ajuda na identificação botânica.

\section{REFERÊNCIAS BIBLIOGRÁFICAS}

Alcoforado-Filho, F. G.; Sampaio, E. V. S. B. \& Rodal, M. J. N. 2003. Florística e fitossociologia de um remanescente de vegetação caducifólia espinhosa arbórea em Caruaru, Pernambuco. Acta Botanica Brasilica 14(2): 287-303.

Andrade, M. C. O. 1999. Atlas escolar de Pernambuco. GRAFSET, João Pessoa, 112p.

Andrade, L. A.; Pereira, I. M.; Leite, U. T. \& Barbosa, M. R. V. 2005. Análise da cobertura de duas fitofisionomias de caatinga, com diferentes históricos de uso, no município de São João do Cariri, Estado da Paraíba. Revista Cerne 11(3): 253-262.

Araújo, E. L.; Sampaio, E. V. S. B. \& Rodal, M. J. N. 1995. Composição florística e fitossociológica de três áreas de caatinga de Pernambuco. Revista Brasileira de Biologia 55(4): 595-607.

Araújo, A.; Santos, M. F. A. V.; Meunier, I. \& Rodal, M. J. N. 2002. Desertificação e seca: contribuição da ciência e da tecnologia para a sustentabilidade do semiárido do Nordeste do Brasil. Gráfica e Editora do Nordeste, Recife, 63p.

Cronquist, A. 1981. An integrated system of classification of flowering plants. 
Columbia University Press, New York, 1262p.

Galindo, I. C. L. 2007. Relações solovegetação em áreas sob processo de desertificação no estado de Pernambuco. Tese de Doutorado. Universidade Federal Rural de Pernambuco, Recife, 232p.

Giulietti, A. M.; Harley, R. M.; Queiroz, L. P.; Barbosa, M. R. V.; Bocage-Neta, A. L. \& Figueiredo, M. A. 2002. Espécies endêmicas da caatinga. In: Sampaio, E. V. S. B.; Giulietti, A. M.; Virgínio, J. \& Gamarra-rojas, C. F. L. Vegetação e flora da Caatinga. Associação Plantas do Nordeste - APNE, Centro Nordestino de Informações sobre Plantas - CNIP, Recife. Pp. 103-118.

Jacomine, P. K. T. 1996. Solos sob caatingas - características e uso agrícola. In: Alvarez, V. H.; Fontes, L. E. F. \& Fontes, M. P. F. O solo nos grandes domínios morfoclimáticos do Brasil e o desenvolvimento sustentado. SBCS, UFV, DPS, Viçosa. Pp. 95-111.

Lovejoy, T. E. 1988. Diverse considerations. In: Wilson, E. O. \& Peter, F. M. Biodiversity. Nacional Academy Press, Washington. Pp. 421-427.

Magurran, A.E. 1989. Diversidad ecológica y su medición. Vedrà, Barcelona, 200p.

Maracajá, P. B.; Batista, C. H. F.; Sousa, A. H. \& Vasconcelos, W. E. 2003. Levantamento florístico e fitosociológico do estrato arbustivo-arbóreo de dois ambientes na Vila Santa Catarina, Serra do Mel, RN. Revista de Biologia e Ciências da Terra 3(2): 25-32.

Margalef, R. 1994. Dynamic aspects of diversity. Journal of Vegetation Science 5: 451-456.

Martins, F. R. \& Santos, F. A. M. 2000. Técnicas usuais de estimativa da biodiversidade. RevistaHolos (edição especial). Pp. 236-267.

Miranda, J. D.; Padilla, F. M. \& Pugnaire, F. I. 2004. Sucesión y restauración en ambientes semiáridos. Ecosistemas 2004/ 1 (http//www.aeet.org/ecosistemas/041/ investigacion4.htm).
Muller-Dombois, D. \& Ellenberg, H. 1974. Measuring species quantites. In: Aims and methods of vegetation ecology. John Wiley \& Sons, New York. Pp. 67-92.

Pereira, I. M.; Andrade, L. A.; Costa, J. R. M. \& Dias, J. M. 2001. Regeneração natural em um remanescente de caatinga sob diferentes níveis de perturbação, no Agreste Paraibano. Acta Botanica Brasilica 15(30): 413-426.

Pereira, I. M.; Andrade, L. A.; Sampaio, E. V. S. B. \& Barbosa, M. R. V. 2003. Useeffects on structure and flora of caatinga. Biotropica 35: 154-165.

Raven, P. H.; Evert, R. F. \& Curtis, H. 1978. Desenvolvimento inicial do organismo vegetal. In: Biologia Vegetal. Guanabara Dois, Rio de Janeiro. Pp. 420-427.

Rodal, M. J. N.; Lins e Silva, A. C. B.; Pessoa, L. M. \& Cavalcanti, A. D. C. 2005. Vegetação e flora fanerogâmica da área de Betânia, Pernambuco. In: Araújo, F. S.; Rodal, M. J. N. \& Barbosa, M. R. V. Análise das variações da biodiversidade do bioma Caatinga: Suporte a estratégias regionais de conservação. Ministério do Meio Ambiente, Brasília. Pp. 140-166.

Rodríguez, A. R.; Mora, J. L.; Arbelo, C. \& Bordon, J. 2005. Plant succession and soil degradation in desertified area (Fuerteventura, Canary Islands, Spain). Catena 59:117-131.

Sampaio, E. V. S. B. 2002. Uso das plantas da caatinga. In: Sampaio, E. V. S. B.; Giulietti, A. M.; Virgínio, J. \& Gamarra-Rojas, C. F. L. Vegetação e flora da caatinga. Associação Plantas do Nordeste - APNE, Centro Nordestino de Informações sobre Plantas - CNIP, Recife. Pp. 49-90.

Sampaio, E. V. S. B.; Sampaio, Y.; Vital, T.; Araújo, S. B. \& Sampaio, G. R. 2003. Desertificação no Brasil: conceitos, núcleos e tecnologias de recuperação e convivência. Ed. Universitária da UFPE, Recife, 202p.

Santana, J. A. S. \& Souto, J. S. 2006. Diversidade e estrutura fitossociológica da caatinga na Estação Ecológica do Seridó- 
RN. Revista de Biologia e Ciências da Terra 6(2): 232-242.

Santos, M. F. A. V.; Ribeiro, M. R. \& Sampaio, E. V.S. B. 1992. Semelhanças vegetacionais em sete solos da caatinga. Pesquisa Agropecuária Brasileira 27: 305-314.

Santos, M. F. A. V.; Gutiérrez, E.; Vallejo, R; Meunier, I. J. \& Cillero, D. 2003. Diversidade da vegetação pós-incêndio em terraços abandonados e ladeiras não cultivadas em Valença, Espanha. Revista Árvore 27(3): 399-405.
Vasconcelos, R. 2002. Estimativa de perdas econômicas provocadas pela desertificação na região do semi-árido. In: Teuchler, $\mathrm{H}$. \& Moura, S. M. Quanto vale a caatinga? Fundação Konrad Adenauer, Fortaleza. Pp. 45-67.

Williamson, M. 1988. Relationship of species number to area, distance and other variables. In: Myers, A. A. \& Giller, P. S. Analytical biogeography. London. Pp. 92-115. 